\title{
RESEARCH
}

Open Access

\section{P53-R273H mutation enhances colorectal cancer stemness through regulating specific IncRNAs}

Yuechao Zhao ${ }^{1+}$, Yiran $\mathrm{Li}^{1+}$, Jie Sheng ${ }^{1}$, Fan $\mathrm{Wu}^{1}$, Kai $\mathrm{Li}^{1}$, Rong Huang ${ }^{1}$, Xiaojuan Wang ${ }^{1}$, Tao Jiao ${ }^{1}$, Xin Guan ${ }^{1}$,

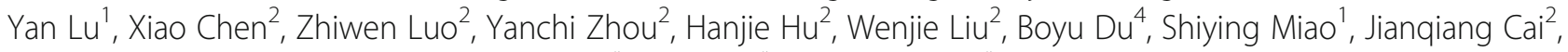
Linfang Wang ${ }^{1}$, Hong Zhao ${ }^{2}$, Jianming Ying ${ }^{3^{*}}$, Xinyu $\mathrm{Bi}^{2^{*}}$ and Wei Song ${ }^{1^{*}}$

\begin{abstract}
Background: TP53 is one of the most frequently mutated genes among all cancer types, and TP53 mutants occur more than 60\% in colorectal cancer (CRC). Among all mutants, there are three hot spots, including p53-R175H, p53-R248W and p53-R273H. Emerging evidence attributes cancer carcinogenesis to cancer stem cells (CSCs). Long noncoding RNAs (IncRNAs) play crucial roles in maintaining the stemness of CSCs. However, it is unknown if mutant p53-regulated IncRNAs are implicated in the maintenance of CSC stemness.

Methods: RNA-sequencing (RNA-seq) and ChIP-sequencing (ChIP-seq) were used to trace the IncRNA network regulated by p53-R273H in HCT116 endogenous p53 point mutant spheroid cells generated by the somatic cell knock-in method. RT-qPCR was used to detect IncRNA expression patterns, verifying the bioinformatics analysis. Transwell, spheroid formation, fluorescence activated cell sorter (FACS), xenograft nude mouse model, tumor frequency assessed by extreme limiting dilution analysis (ELDA), Western blot assays and chemoresistance analysis were performed to elucidate the functions and possible mechanism of Inc273-31 and Inc273-34 in cancer stem cells.

(Continued on next page)
\end{abstract}

\footnotetext{
* Correspondence: jmying@hotmail.com; beexy1971@163.com;

songwei@ibms.pumc.edu.cn

${ }^{\dagger}$ Yuechao Zhao and Yiran Li contributed equally to this work.

${ }^{3}$ Department of Pathology, State Key Laboratory of Molecular Oncology, National Cancer Center/National Clinical Research Center for Cancer/Cancer Hospital, Chinese Academy of Medical Sciences and Peking Union Medical College, Beijing 100021, China

${ }^{2}$ Department of Hepatobiliary Surgery, State Key Laboratory of Molecular Oncology, National Cancer Center/National Clinical Research Center for Cancer/Cancer Hospital, Chinese Academy of Medical Sciences and Peking Union Medical College, Beijing 100021, China

'Department of Biochemistry and Molecular Biology, State Key Laboratory of

Medical Molecular Biology, Institute of Basic Medical Sciences Chinese

Academy of Medical Sciences, School of Basic Medicine Peking Union

Medical College, Beijing 100005, China

Full list of author information is available at the end of the article
}

(c) The Author(s). 2019 Open Access This article is distributed under the terms of the Creative Commons Attribution 4.0 International License (http://creativecommons.org/licenses/by/4.0/), which permits unrestricted use, distribution, and reproduction in any medium, provided you give appropriate credit to the original author(s) and the source, provide a link to the Creative Commons license, and indicate if changes were made. The Creative Commons Public Domain Dedication waiver (http://creativecommons.org/publicdomain/zero/1.0/) applies to the data made available in this article, unless otherwise stated. 
(Continued from previous page)

Results: p53-R273H exhibited more characteristics of CSC than p53-R175H and p53-R248W. RNA-seq profiling identified 37 up regulated and 4 down regulated differentially expressed IncRNAs regulated by $\mathrm{p} 53-\mathrm{R} 273 \mathrm{H}$. Combined with ChIP-seq profiling, we further verified two IncRNAs, named as Inc273-31 and Inc273-34, were essential in the maintenance of CSC stemness. Further investigation illustrated that Inc273-31 or Inc273-34 depletion dramatically diminished colorectal cancer migration, invasion, cancer stem cell self-renewal and chemoresistance in vitro. Moreover, the absence of Inc273-31 or Inc273-34 dramatically delayed cancer initiation and tumorigenic cell frequency in vivo. Also, Inc273-31 and Inc273-34 have an impact on epithelial-to mesenchymal transition (EMT). Finally, Inc273-31 and Inc273-34 were significantly highly expressed in CRC tissues with p53-R273H mutation compared to those with wildtype p53.

Conclusions: The present study unveiled a high-confidence set of IncRNAs regulated by p53-R273H specific in colorectal CSCs. Furthermore, we demonstrated that two of them, Inc273-31 and Inc273-34, were required for colorectal CSC selfrenewal, tumor propagation and chemoresistance. Also, the expression of these two IncRNAs augmented in colorectal cancer patient samples with p53-R273H mutation. These two IncRNAs may serve as promising predictors for patients with p53-R273H mutation and are vital for chemotherapy.

Keywords: p53, IncRNAs, Colorectal cancer, Cancer stem cell

\section{Background}

Evidence has indicated that $90 \%$ of mortality from cancer is attributable to metastases [1], including colorectal cancer [2]. Cancer stem cells (CSCs) display more migratory capability than other tumor cells [3]. Despite a small population, CSCs are considered as tumor-initiating cells in colorectal cancer and many other types of cancer. CSCs exhibit self-renewal ability and can propagate diverse cells that constitute the tumor [4]. A single allele mutation in TP53 leads to both loss of tumor-suppressive functions (LOF) and gain of oncogenic functions (GOF) [5]. Among single allele mutant types, there are three 'hot-spot' mutations that are categorized into the following two types: conformational mutations, such as $\mathrm{R} 175 \mathrm{H}$; and DNA-contact mutations represented by $\mathrm{R} 248 \mathrm{~W}$ and $\mathrm{R} 273 \mathrm{H}$ [6]. Recent studies have demonstrated that somatic mutations in TP53 (p53-R273H) play critical roles in chemotherapy-induced colorectal CSC, but the underlying lncRNAs changes invovled in this process is not completely understood [7].

Long noncoding RNAs (lncRNAs) have been reported to play critical roles in maintaining stemness of cancer stem cells and chemoresistance [8]. Abnormal expression of lncRNAs reflects their different roles in the progression of colorectal cancer $[9,10]$. Increasing evidence has shown that many lncRNAs play roles in the pathogenesis and progression of different kinds of cancers [11]. It had been reported that wildtype p53, as an important transcript factor, could regulate lncRNAs transcription under DNA damage or UV stress [12, 13]. Thus, considering the robust transcript function of mutant p53 in cancer development $[14,15]$, it is reasonable to speculate that mutant p53 may change its downstream lncRNAs regulation networks and endow tumor cells with stemness. However, a comprehensive mutant p53-regulated lncRNA network in colorectal CSC remain elusive.

In this study, we integrate genome-wide expression data obtained by RNA sequencing (RNA-seq) with p53R273H ChIP-seq data of human colorectal cancer cells in CSC state. The combination of these experimental approaches allowed us to illustrate p53-R273H specific regulated lncRNA network, and two of the lncRNAs were found to be required for colorectal CSC self-renewal, tumor propagation and chemoresistance. We also show that the expression of p53-R273H-regualed lncRNAs increased in colorectal cancer patient samples with p53-R273H mutation. In summary, we defined a highconfidence set of 41 lncRNAs that are p53-R273H transcriptional targets and demonstrated two of the p53-R273H-regulated lncRNAs are required for colorectal cancer stemness maintenance and chemoresistance.

\section{Methods \\ Cell lines and cell culture}

The human HCT116 CRC cell line was obtained from the Cell Resource Center of Peking Union Medical College (Beijing, China). The HCT116 p53-/- cell line was generated in our lab. HCT116 p53-/- and HCT116 p53 endogenous point mutant cell lines were cultured in Iscove's Modified Dulbecco's Medium (HyClone, USA) with $10 \%$ fetal bovine serum (FBS, Gibco, USA) and 1\% penicillin/streptomycin (Gibco, USA). When cells reached 80-90\% confluence, cell passage was conducted, and cells in logarithmic growth phase were collected for use. Cells were confirmed to be free of mycoplasma using the Bimake mycoplasma detection kit. HCT116 p53 endogenous point mutant cell lines were constructed as shown in Additional file 1, S2A. 


\section{Cell migration and invasion assay}

The cell invasive and migratory ability was detected using an $8 \mu \mathrm{m}$ pored, $6.5 \mathrm{~mm}$ polycarbonate transwell filter (Corning, USA), according to our previous study [16]. For the cell migration assay, $5 \times 10^{5}$ cells in serumfree IMDM were seeded in the upper chamber and the lower chamber contained complete IMDM with 10\% FBS $(0.5 \mathrm{~mL})$. After incubation for $36-48 \mathrm{~h}$, the cells were fixed with paraformaldehyde and stained with $0.1 \%$ Crystal Violet (Beyotime, Jiangsu, China) for $0.5 \mathrm{~h}$. Cells were counted using a microscope. For the cell invasion assay, chamber was uniformly coated with Matrigel basement membrane matrix (BD Biosciences, USA) and incubated at $37^{\circ} \mathrm{C}$ for $4 \mathrm{~h}$ to form the Matrigel layer in the chamber. The following procedures were the same as migration assay. The migration and invasion experiments were performed in triplicate.

\section{Spheroid-forming assay}

The spheroid-forming assay was conducted as previous study with little modification [17]. Cells lines were plated in 6-well, ultra-low attachment plates (Corning Life Sciences) at a density of 3000 viable cells per well. Cells were grown in spheroid medium consisting of DMEM/ F12 (Invitrogen) supplemented with B27 serum-free supplement (1:50; Invitrogen), $20 \mathrm{ng} / \mathrm{ml}$ epidermal growth factor (R\&D Systems), $20 \mathrm{ng} / \mathrm{ml}$ basic fibroblast growth factor (R\&D Systems), and penicillin-streptomycin at $37^{\circ} \mathrm{C}$ in $5 \% \mathrm{CO}_{2}$. The experiment was terminated after 10-12 days, and the spheroids were quantified.

\section{RNA isolation and reverse transcription quantitative PCR (RT-qPCR)}

Total RNA derived from spheroids or cells was extracted using RNeasy Plus Mini Kit (QIAGEN) according to the manufacturer's protocols. A total of $1 \mu \mathrm{g}$ RNA sample was used to synthesized first-strand cDNA using random hexamers and RevertAid First Strand cDNA Synthesis Kit (Thermo Fisher Scientific) according to manufacturer's instructions. Reverse transcription quantitative PCR (RT-qPCR) reactions including $1 \mu \mathrm{L}$ cDNA were carried out in $20-\mu \mathrm{L}$ reactions using PowerUp ${ }^{\mathrm{mw}} \mathrm{SYBR}^{\mathrm{mu}}$ Green Master Mix (Applied Biosystems) and $0.5 \mathrm{mM}$ specific primers performed by a BioRad CFX Manager Real-Time PCR system. The cycling conditions comprised $10 \mathrm{~min}$ polymerase activation at $95^{\circ} \mathrm{C}$ and 40 cycles at $95^{\circ} \mathrm{C}$ for $15 \mathrm{~s}$ and $60^{\circ} \mathrm{C}$ for $1 \mathrm{~min}$. Actin was used as an internal control. All samples were normalized to internal controls, and fold changes were calculated through relative quantification as follows: $2-[(\mathrm{Ct}$ of gene)-(Ct of Actin)]. Primer sequences are listed in Additional file 1: Table S1.

\section{LncRNA interference and cell transfection}

ASO pools targeting lnc273-31 and lnc273-34 as well as one negative control ASO pool were obtained from Ribo Tech (Shanghai, China). Briefly, 50-100 nM of each ASO pool was introduced in cells using RNAiMAX Transfection Reagent (Invitrogen) according to the manufacturer's instructions. Sequences of ASO targeting lnc273-31 or lnc273-34 are shown in Additional file 1: Table S2. Corresponding negative control (NC) was carried out simultaneously.

\section{Induction of oxaliplatin resistant cell lines}

The construction of chemo-resistant cell lines were constructed according to these two studies with a little modification $[18,19]$. Oxaliplatin-resistant HCT116 p53 endogenous point mutant cell lines were derived from original parental cell line by continuous exposure to stepwise increasing concentrations of oxaliplatin (Bimake, USA). Initially, the exponentially growing cells were exposed to $2 \mu \mathrm{M}$ oxaliplatin for $2-3$ passages. The surviving cells were then exposed to gradually increasing concentrations of oxaliplatin from $0.5 \mu \mathrm{M}$ to $1 \mu \mathrm{M}$ during every passage. This development period was carried out for about 9 months. The final concentration of oxaliplatin is $20 \mu \mathrm{M}$. Generation of cell lines with acquired resistance to oxaliplatin was listed in Table 1. Additionally, vehicle treated parental cell line was kept in culture during this period as control cell line.

\section{Cytotoxicity assay}

Cytotoxicity assay was assessed using CCK8 (Cell Counting Kit-8, Dojindo, Japan) according to a previous study [20]. Cells were plated into 96-well plates at an initial density of $1 \times 10^{4}$ cells/well for $24 \mathrm{~h}$ with $100 \mu \mathrm{L}$ of medium and cultured with increased concentrations of oxaliplatin for $72 \mathrm{~h}$. After the incubation, $10 \mu \mathrm{L}$ of CCK- 8 solution with $90 \mu \mathrm{L}$ fresh medium was then added and incubated for $1 \mathrm{~h}$. The absorbance was measured at $450 \mathrm{~nm}$ using an ELISA plate reader. Sensitivity to drugs was expressed in terms of the concentration of drug required to inhibit 50\% of cell growth (IC50). The cell variability curves were plotted and IC50 values were determined through non-linear regression analysis using Graph Pad Prism software.

\section{Aldefluor assay and cell sorting}

Cell populations with high ALDH1A1 enzymatic activity were identified with the Aldefluor kit (StemCell Technologies, Vancouver, BC, Canada) according to the manufacturer's protocols. Briefly, $2 \times 10^{6}$ cells were re-suspended in $1 \mathrm{~mL}$ Aldefluor buffer and $1 \mu \mathrm{L}$ Aldefluor reagent in the presence or absence of the specific ALDH1A1 inhibitor for $30 \mathrm{~min}$ at $37^{\circ} \mathrm{C}$. Brightly fluorescent ALDH1A1positive cells were detected in the green fluorescence channel, FL1, and samples treated with the specific 
Table 1 Generation of cell lines with acquired resistance to oxaliplatin

\begin{tabular}{lllll}
\hline Cell line & Initial Conc. & Final Conc. & Exposure passages & Exposure time \\
\hline HCT116 p53-ctrl & $2 \mu \mathrm{M}$ & $20 \mu \mathrm{M}$ & 53 & 9 months \\
HCT116 p53-R273H & $2 \mu \mathrm{M}$ & $20 \mu \mathrm{M}$ & 53 & 9 months
\end{tabular}

ALDH1A1 inhibitor, DEBA, were used as the control to set the gates defining the ALDH1A1-positive region. Flow cytometry was performed using BD Accuri ${ }^{\text {TM }}$ C6 instrument (BD Biosciences, San Jose, CA) as well as the data analyzing. For cell sorting, the cells were sorted a Moflo ${ }^{\text {тм }}$ XDP high-performance cell sorter (Beckman Coulter, Brea, CA, USA). After sorting, the cells were washed and cultured for detection of lncRNA expression.

\section{Chromatin immunoprecipitation (ChIP)}

ChIP assays were performed using a SimpleChIP Plus Sonication Chromatin IP Kit (Cell signaling Technology, \#56383) with little modification. Spheroid cells $\left(10^{7}\right)$ were crosslinked with $1 \%$ formaldehyde for $5 \mathrm{~min}$. Glycine was then added to a final concentration of $0.125 \mathrm{M}$ for 5 min. Chromatin was disrupted by a Covaris S220 (power of $200 \mathrm{~W}$ and duty factor of 2.0) for $10 \mathrm{~min}$. ChIPqPCR primers are listed in Additional file 1: Table S3.

\section{Sequencing libraries preparation}

Total RNA and ChIP DNA were isolated as described before. Novogene Technology Co., Ltd. (Tianjin, China) was trusted to prepare the libraries and perform the sequencing.

\section{RNA-sequencing data analysis}

Paired-end and strand-specific RNA-seq libraries were prepared based on llumina instructions, and then sequenced on HiSeq 2000 (Illumina), of which the sequence length was set as $150 \mathrm{bp}$. GENCODE v27 (GRCh38.p10) assembly of the human genome was offered for annotation of the gene loci as reference. The HISAT2 [21] mapper (v2.1.0) generated the genome index and mapped reads to this human genome. StringTie [22] was applied to assemble the alignments, construct multiple isoforms and measure the expression of all genes and transcripts. Ballgown [23] was employed to analysis the expression levels of transcripts from StringTie and to estimate which transcripts were differentially expressed. LncRNAs or genes were considered significant if the false discovery rate (FDR) was less than 0.05 .

\section{ChIP-sequencing data and p53 motif analysis}

Bowtie (version 1.2.2) [24] was used to assemble raw sequence files to human genome. Peak detection and signal intensity analyses for ChIP-seq data were performed using MACS14 [25] and HOMER [26]. The binding site sequences matching to enriched regions were used to conduct the de novo motif search, which demanded the differentially selection of genes.

\section{Functional enrichment analysis}

The Spearman rank correlation was devoted to detect the co-expression relationship between lncRNAs and protein-coding genes regulated by $\mathrm{p} 53-\mathrm{R} 273 \mathrm{H}$. A list of co-expressed genes of individual lncRNA regulated by p53-R273H were identified under a given threshold (coefficient $>0.9$, coefficient $<-0.9$ and FDR $<0.05$ ). The potential combinative impact of IncRNA regulated by p53-R273H, was estimated by the functional enrichment analysis, containing the Gene Ontology (GO) and Kyoto Encyclopedia of Genes and Genomes (KEGG) pathways. A standard hypergeometric distribution was devoted to measure the significant $P$-values. Multiple hypothesis testing was performed using Benjamini \& Hochberg (BH) method.

\section{Xenograft growth in nude mice}

For subcutaneous injection models, serial dilutions (500, $5000,50,000,500,000$ or 5000,000) of control and knock-down cells were implanted into two sides of the same nude mouse at the posterior dorsal flank region (male BALB/c nude mice; aged 4 to 6 weeks; $n=5$ per group) with a Matrigel scaffold (BD Matrigel matrix, BD Biosciences). Tumors were measured every three days. Animal experiments were performed with the approval of Peking Union Medical College Animal Care and Use Committees. Mice were maintained under standard conditions according to the institutional guidelines for animal care. Tumorigenic cell frequency was calculated based on ELDA analysis (http://bioinf.wehi.edu.au/software/elda/). The statistical $p$ value was obtained using a Chi-squared test.

\section{Tissue analyzes}

The colorectal cancer FFPE tissues were obtained from the Cancer Hospital, Chinese Academy of Medical Sciences, used for RT-qPCR analysis. Prior patient consent and approval from the Institutional Research Ethics Committee were obtained for the use of these patient specimens for research purposes. The study was conformed to the ethical guidelines of the Declaration of Helsinki. The tissues were divided into two groups according to their p53 status detected by RNA-seq, which were p53 wildtype $(n=10)$ and $\mathrm{p} 53-\mathrm{R} 273 \mathrm{H}$ mutation $(n=15)$. Total RNA derived from FFPE tissues was extrated using AllPrep DNA/ 
RNA FFPE Kit (QIAGEN, 80234) according to manufacturer' instruction.

\section{Statistical analysis}

Data were presented as mean $\pm S D$ and analyzed by GraphPad Prism software. Student's t-test was performed to analyze continuous variable. Association between IncRNA expression and clinicopathologic parameters were obtained from SPSS software. $P<0.05$ was considered to be statistically significant.

\section{Results}

P53-R273H exhibits more invasive ability than p53-R175H and $\mathrm{p} 53-\mathrm{R} 248 \mathrm{~W}$ and promotes CSC expansion in vitro and in vivo

To examine the biological differences among the three hot-spot mutations in cancer stem cell state, R175H, R248W and R273H were overexpressed (OE) in HCT116 p53-/- cells and confirmed by Western blot (Additional file 1: Figure S1A). Migration assays showed that p53$\mathrm{R} 273 \mathrm{H}-\mathrm{OE}$ had more significantly elevated migratory capabilities than p53-R175H-OE and p53-R248W-OE, which agreed with the invasion assay results (Fig. 1a). The roles of the three hot-spot mutations in CSC formation and self-renewal were next investigated. The spheroid-forming assay showed that all three mutations improved CSC formation, especially for p53-R273H-OE, as demonstrated by significantly increased spheroid size and numbers in first and secondary spheroid formation as compared to WT rescue-OE (Fig. 1b). The expression levels of cancer stemness-related genes, namely, Sox2, Oct 4 and Nanog, were examined. Only the R273H mutation showed increased expression of these genes compared to WT rescue-OE (Fig. 1c). Collectively, these findings demonstrated that the p53-R273H mutation has more invasive and expansion ability compared to the other two p53 mutations.

Endogenous heterozygous p53-R273H point mutant (p53-R273H-PM) HCT116 cells were generated using somatic cell knock-in technology as previously described (Additional file 1: Figure S2A) [27]. The cell model was confirmed by Sanger sequencing (Additional file 1: Figure S2B). As observed in p53-R273H-OE cells, p53-R273H-PM cells exhibited the similar increased invasive and migratory ability compared to p53-ctrl cells (Fig. 2a). Colorectal CSCs were enriched and self-renewal was assessed by 1st and 2nd spheroid formation. The spheroid size and numbers of p53-R273H mutation significantly increased when compared to p53-ctrl (Fig. 2b). And the expression of stemness-related genes was much higher in $\mathrm{p} 53-\mathrm{R} 273 \mathrm{H}$ spheroids than that in p53-ctrl spheroids (Fig. 2c).

There are two widely recognized methods to measure the stemness of cancer cells, spheroid-forming assay and flow cytometry to analyze specific molecular markers.
Next we further asked the percentage of CSC markers of colorectal caner stem cells, ALDH [28, 29]. The frequency of the $\mathrm{ALDH}^{+}$population was determined using an Aldefluor assay. As shown in Fig. 2d, approximately $28.4 \%$ of the cells were $\mathrm{ALDH}^{+}$in p53-ctrl cells while $42.1 \%$ in $\mathrm{p} 53-\mathrm{R} 273 \mathrm{H}$ cells, which decreased to $<0.1 \%$ in both cells in the presence of diethylaminobenzaldehyde (DEAB) (an ALDH inhibitor), indicating the elevatory percentage of cancer stem cells in p53-R273H cells. In order to define the tumorigenic capacity of p53-R273H, p53-R273H-PM and p53-ctrl spheroid cells were subcutaneously implanted into BALB/c nude mice followed by an ELDA analysis. P53-R273H mutation resulted in a much stronger tumor presence compared with p53-ctrl spheroid cells as assessed by a limiting dilution xenograft analysis (Fig. 2e), suggesting that p53-R273H mutation increased tumor initiating capacity. P53-R273H led to 12 mice harboring tumors among 20 mice, while only 7 mice implanted with p53-ctrl harbored tumors (Fig. 2e). Moreover, p53-R273H mutation significantly increased xenograft tumor growth (Fig. 2f). Compared to p53-ctrl cells, p53-R273H-PM cells formed a tumor at a lower dilution rate (Fig. 2g), indicating the strong CSC frequency of p53-R273H. Overall, p53-R273H mutation enhances the tumorigenic capacity of colorectal CSCs.

\section{Global profiling and identification of $\mathrm{p} 53-\mathrm{R} 273 \mathrm{H}-$ regulated IncRNAs}

To unveil the genome-wide transcripts regulated by p53-R273H in the CSC state, HCT116 p53-R273H-PM spheroids were enriched, and the polyadenylated RNA fraction was isolated and used to perform strand-specific paired-end RNA Illumina sequencing. The workflow of the study design is illustrated in Fig. 3a. In total, 218,713 transcripts were successfully assembled, and $85 \%$ of the transcripts were annotated according to Gencode (version 27; GRCh38.p10) (Additional file 1: Figure S3A). Among the annotated transcripts, $75.6 \%(160,142)$ were identified as protein-coding mRNAs, and the remaining $24.4 \%$ were classified as different types of noncoding transcripts (Additional file 1: Figure S3B). In total, 13.4\% $(29,201)$ of transcripts were defined as lncRNAs, including antisense, intergenic, processed transcripts, sense-intronic and sense overlapping lncRNAs, and 2.3\% (5032) of annotated transcripts corresponded to other types of noncoding RNAs, such as transcripts derived from pseudogenes, retained introns and pri-microRNAs (Additional file 1: Figure S3B).

To identify differentially expressed lncRNAs in cancer stem cells, p53-ctrl and p53-R273H spheroid cells were compared via Ballgown. In total, 41 lncRNAs were found differentially expressed with 37 up regulated and 4 down regulated (Fig. 3b; Additional file 2: adjust $P<0.05, \log _{2-}$ Fold Change $>1$ or $<-1$ ). The validation results of these 


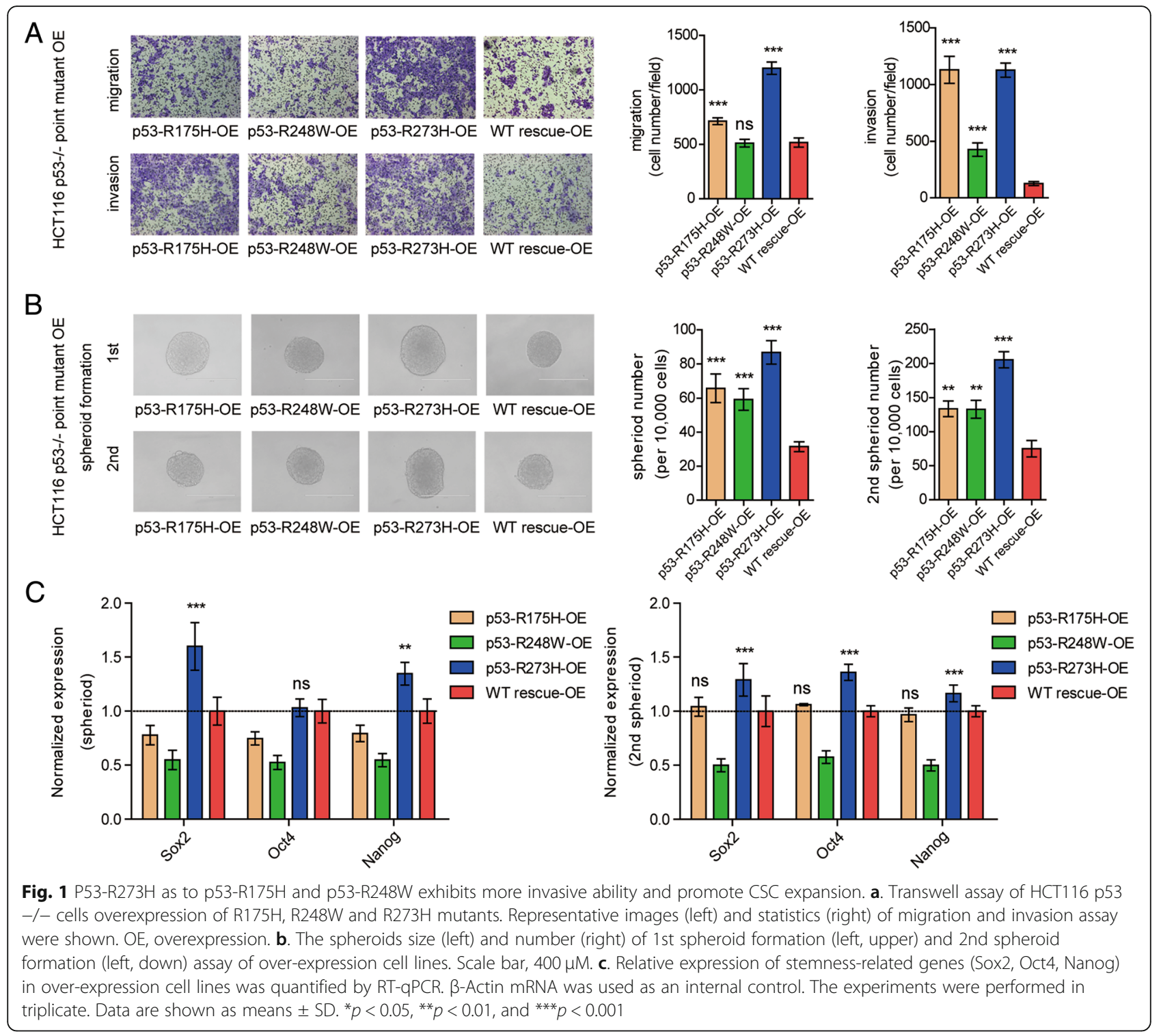

41 lncRNAs were shown in Additional file 1: Figure S4A, using RT-qPCR. In summary, we have successfully validated 36 out of 37 up regulated lncRNAs and 3 out of 4 down regulated lncRNAs. Gene ontology $(\mathrm{GO})$ analysis and KEGG pathway analysis were conducted on these up regulated lncRNAs to enrich the involved signaling pathways (Fig. 3c-d). CSC-related signaling pathways, such as drug resistance [30], JAK-STAT [31], MAPK [32] and Wnt [33] were enriched, further supporting the hypothesis that the subset of lncRNAs regulated by $\mathrm{p} 53-\mathrm{R} 273 \mathrm{H}$ is specific to CSC. The functional analysis results of down regulated lncRNAs are listed in Additional file 3 and the differentially expressed protein coding genes are listed in Additional file 4.

The 36 up regulated lncRNAs were ranked by stemness score according to a previous description [34], and the top 10 IncRNAs were screened for further analysis, which namely as RP11 - 288 L9.4, CH17 - 80A12.1, SERPINB9P1, TNRC6C - AS1, RP11 - 817 J15.2, RP11 - 89 K21.1, BISPR, LINC01588, TMEM51 - AS1 and SH3PXD2A - AS1 (ranked 1 to 10) (Fig. 3e). To evaluate the co-expression relationship between the top 10 lncRNAs and well-known CSC-related genes, a heatmap of co-occurrence was generated with red and blue representing correlation values greater than 0.99 and less than 0.85 , respectively. The top 10 lncRNAs had strong co-occurrence with the CSC-related genes (Fig. 3f), suggesting that lncRNAs regulated by p53-R273H are correlated with CSCs.

\section{Lnc273-31 and Inc273-34 are specifically regulated by p53-R273H in colorectal CSCs}

Considering the up regulated lncRNAs in p53-R273H cells may be caused by its GOF as a transcript factor, ChIP-seq was performed to discern p53-R273H direct targets. In the 


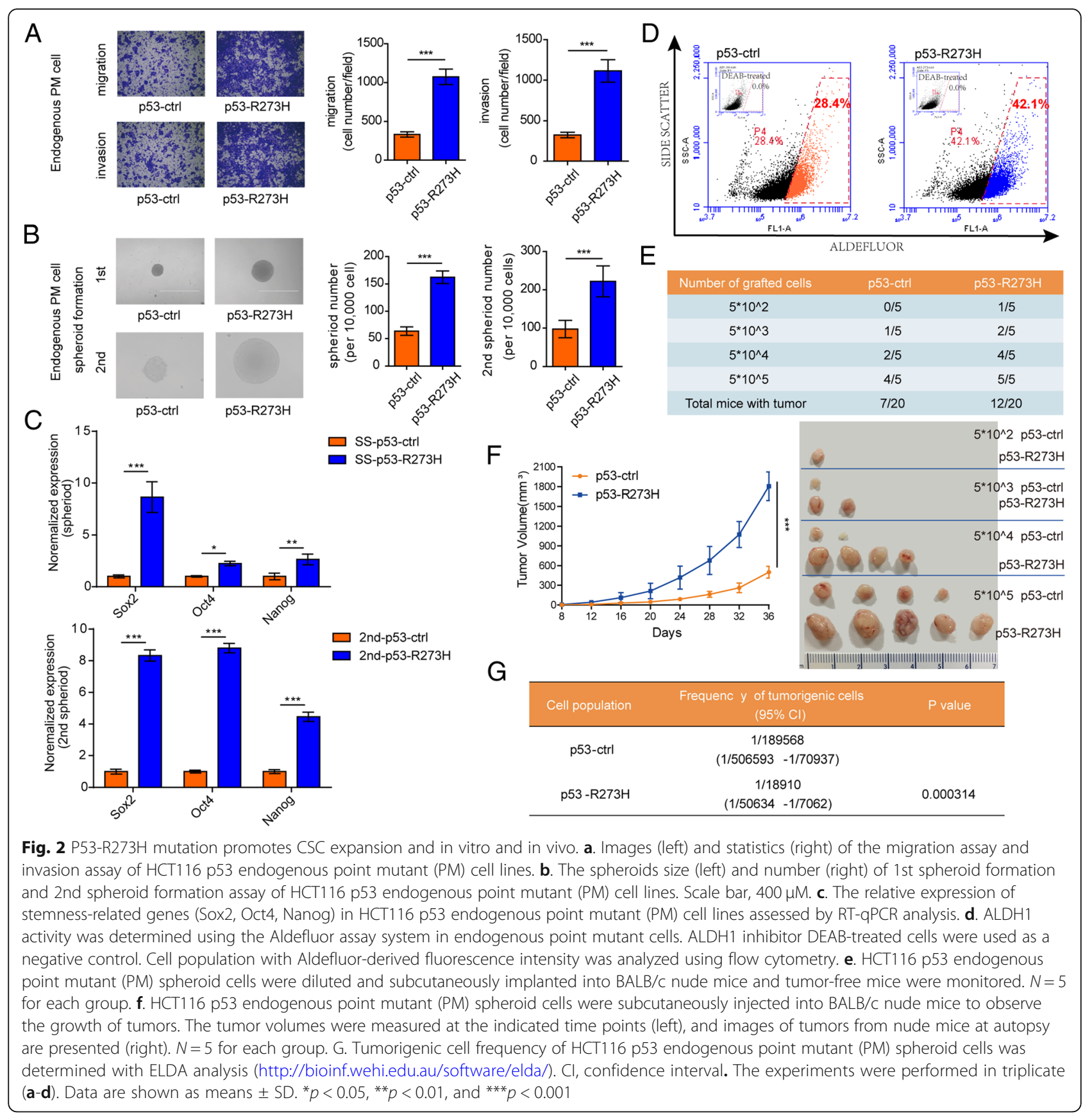

p53-R273H spheroid cells, 14,063 p53 peaks were identified, and 11,010 peaks were identified in p53-ctrl spheroid cells (Fig. 4a). Interestingly, the signal distribution of p53 peaks bound with mRNAs was within ten, while peaks associated with lncRNAs were less than five (Fig. 4b). In total, 3840 lncRNAs were regulated by p53-R273H, and 1196 of which were annotated by Gencode v27 as intergenic lncRNAs (608), antisense lncRNAs (566) or processed transcripts (22) (Additional file 5).

To further trace p53-R273H regulated lncRNAs in the CSC state, ChIP-seq analysis was combined with RNA- seq analysis, which identified 7 lncRNAs regulated by p53-R273H (short for lnc273s, Additional file 6). Among these IncRNAs, two IncRNAs, which were also present in the top 10 lncRNAs ranked by stemness score, and named TMEM51-AS1 as lnc273-31 and SH3PXD2A-AS1 as lnc273-34 (Fig. 4c). A circos plot was then generated to show the genome-wide distribution of the top 100 co-expressed genes related to the location of lnc273-31 and lnc273-34 using circlncRNAnet [35] (Fig. 4d). Consistent with the binding of p53, the p53 consensus motif was highly enriched across the p53-bound loci 


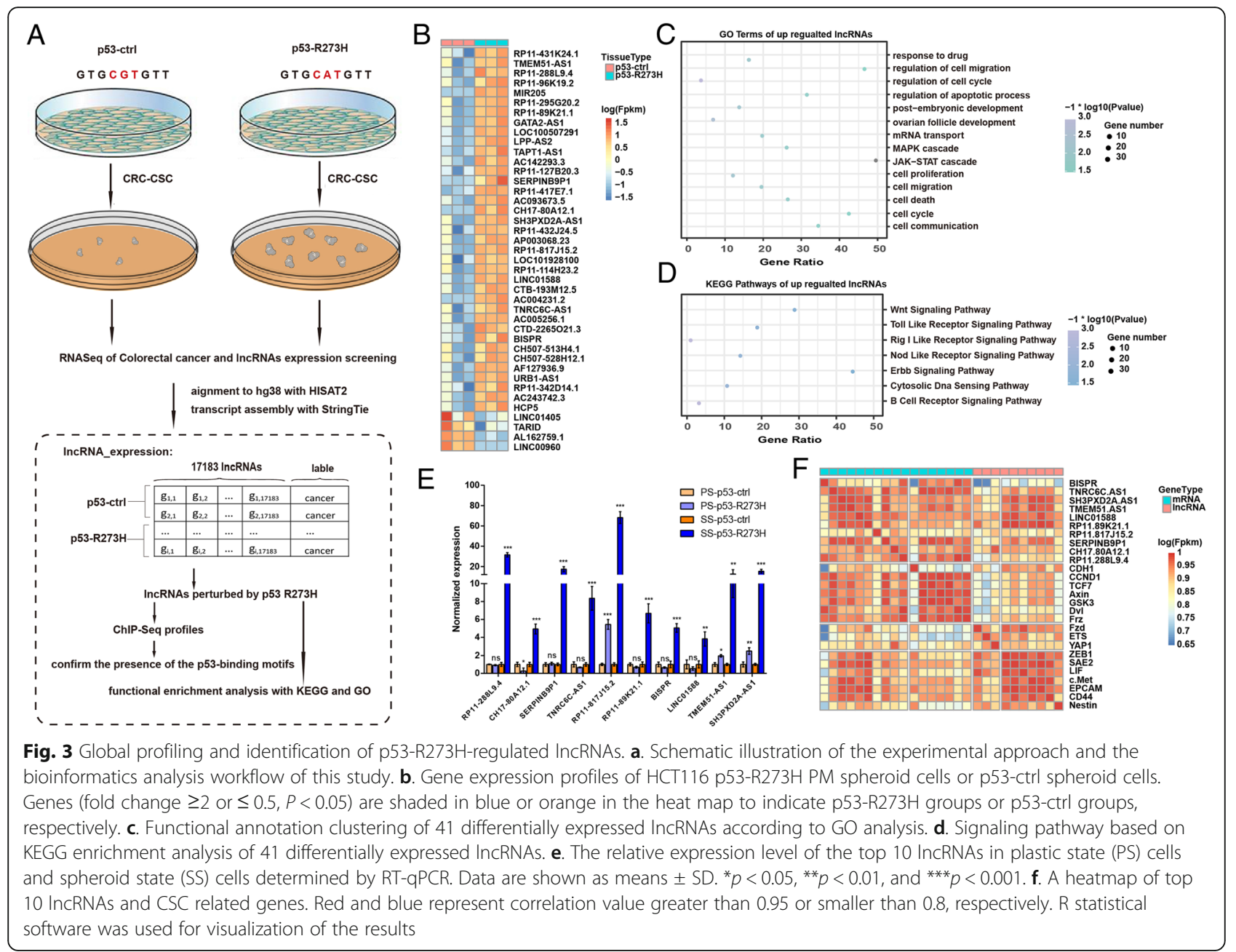

(Fig. 4e), confirming the presence of p53REs in these genomic regions.

\section{Knockdown of Inc273-31 or Inc273-34 inhibits the self-renewal maintenance of colorectal CSC in vitro and in vivo}

To determine the functions of lnc273-31 and lnc273-34 in colorectal cancer cells, antisense oligonucleotides (ASOs) were designed to reduce target lncRNA expression levels. Knock-down of lnc273-31 or lnc273-34 in either p53-ctrl cells or p53-R273H cells, dramatically decreased the invasive and migratory capability compared to negative control (NC), especially in p53-R273H cells (Fig. 5a). Furthermore, knocking down of lnc273-31 or lnc273-34 significantly impaired the spheroid formation abilities, including spheroid size and spheroid number, indicating the attenuated generation of colorectal CSCs and self-renewal capabilities (Fig. 5b). Moreover, lnc273-31 and lnc273-34 depletion significantly reduced the expression of stemness-related genes compared to NC, shown in Additional file 1: Figure S7A.
Next we detected the frequency of the $\mathrm{ALDH}^{+}$population in lnc273-31 or lnc273-34 depleted cells. In p53-ctrl cells, the frequency of the $\mathrm{ALDH}^{+}$population decreased from $32.9 \%$ in NC cells to $28.8 \%$ or $24.6 \%$, when knocking down lnc273-31 or lnc273-34, respectively. While in p53-R273H cells, ALDH positive percentage decreased from $44.7 \%$ in NC cells to $15.0 \%$ or $17.9 \%$, when lnc $273-$ 31 or lnc273-34 depletion, respectively (Fig. 5c). This results further supported the conclusion that p53-R273Hregulated lncRNAs are essential for the CSC maintenance.

The effect of lnc273-31 and lnc273-34 on tumor-initiating capacity was next assessed by ELDA analysis. The p53-R273H and p53-ctrl spheroid cells with stable lnc273-31 or lnc273-34 knockdown as well as the respective NC spheroid cells were subcutaneously injected into BALB/c nude mice. Lnc273-31 or lnc273-34 depletion resulted in more tumor-free mice compared to $\mathrm{NC}$, indicating lnc273-31 and lnc273-34 depletion attenuated tumor initiating capacity. Two or one out of 20 mice harbored tumors with lnc273-31 or lnc273-34 knockdown, respectively, while 11 or 12 mice harbored 


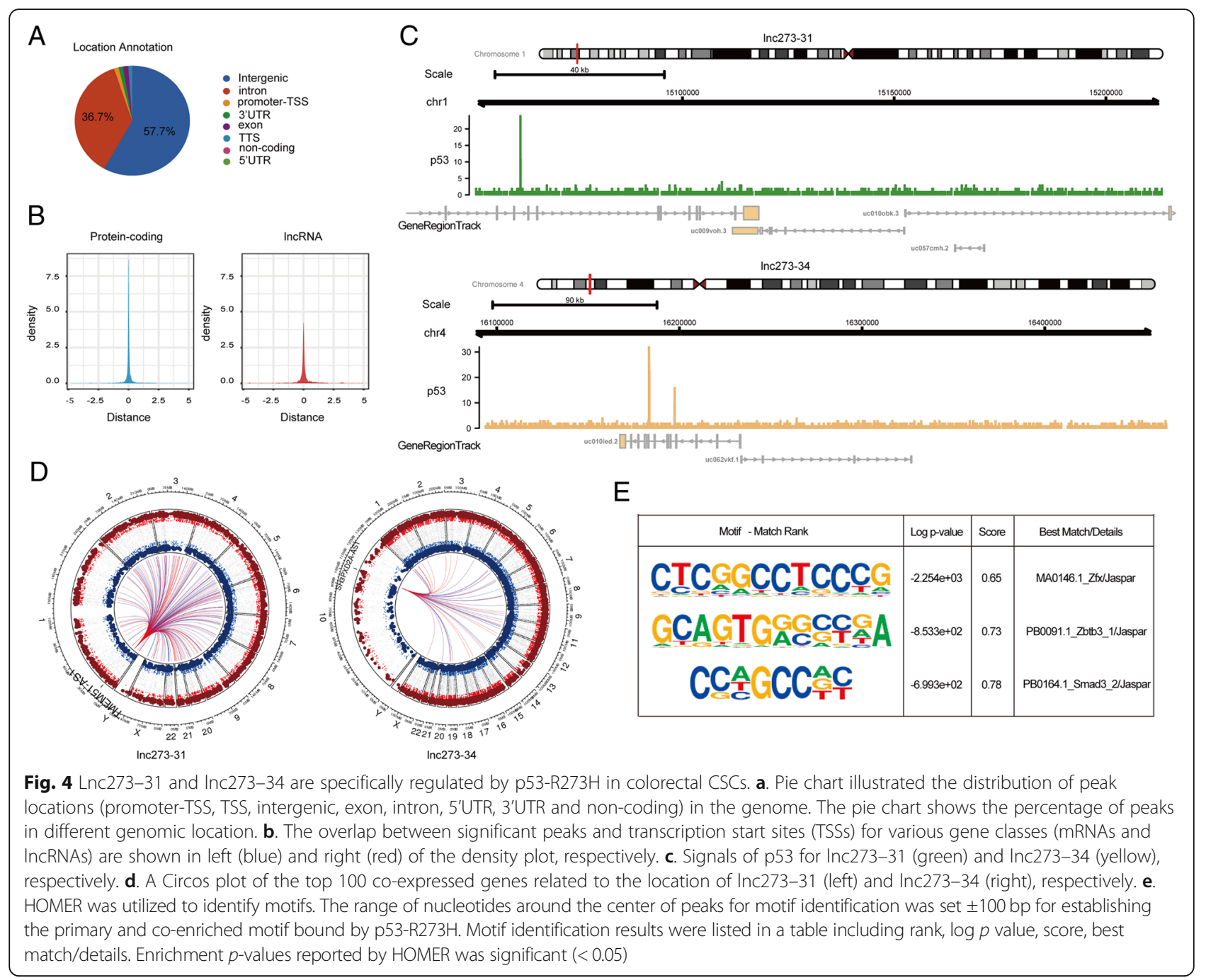

tumors in the NC group (Fig. 5d). The results were more significant in $\mathrm{p} 53-\mathrm{R} 273 \mathrm{H}$ groups compared to p53-ctrl ( 3 out of 20 mice harbored tumors in p53-ctrl groups compared to 1 or 2 mice in knockdown groups), suggesting that lnc273-31 and lnc273-34 are closely related to tumor-initiating capacity. Meanwhile, knockdown of lnc273-31 or lnc273-34 significantly reduced the size of xenograft tumor growth (Fig. 5e). The tumorigenic cell frequency decreased sharply after knockdown of lnc273-31 or lnc273-34 (Fig. 5f). Overall, lnc273-31 or lnc273-34 silencing abrogates the tumorigenic capacity of colorectal CSCs.

\section{P53-R273H-regulated IncRNAs are implicated in} oxaliplatin resistance in colorectal cancer stem cells

To determine if lnc273-31 and lnc273-34 react with oxaliplatin, p53-R273H spheroids were exposed to different concentrations of oxaliplatin, and the expression of lncRNAs was examined. Surprisingly, oxaliplatin treatment induced lnc273-31 expression in a concentration- dependent manner, but the expression of lnc273-34 did not show the same trend (Fig. 6a). Further analysis of the expression levels of lnc273-34 in p53-ctrl and p53$\mathrm{R} 273 \mathrm{H}$ cells demonstated that the expression level in p53-R273H cells was much higher than that in p53-ctrl cells, indicating the regulatory function of $\mathrm{p} 53-\mathrm{R} 273 \mathrm{H}$ in this chemo-reaction process.

Knockdown of either lnc273-31 or lnc273-34 significantly decreased the IC50 of oxaliplatin in p53-ctrl cells from 10.18 to 2.709 or 2.203 , and the decrease in the IC50 of oxaliplatin in p53-R273H was more significant from 16.95 to 1.645 or 1.773 (Fig. 6b). Next we constructed endogenous p53 PM cell lines resistant to oxaliplatin, which were named as p53-ctrl-oxa and p53-R273H-oxa. In oxaliplatin-resistant cell lines, the expression levels of lnc273-31, lnc273-34 and stemness-related genes were much higher than those in the parental cell lines with more than 10-fold increases in p53-R273H-oxa and at least 3-fold increases in p53-ctrl-oxa cells (Fig. 6c). The expression levels were also much higher in oxaliplatin- 


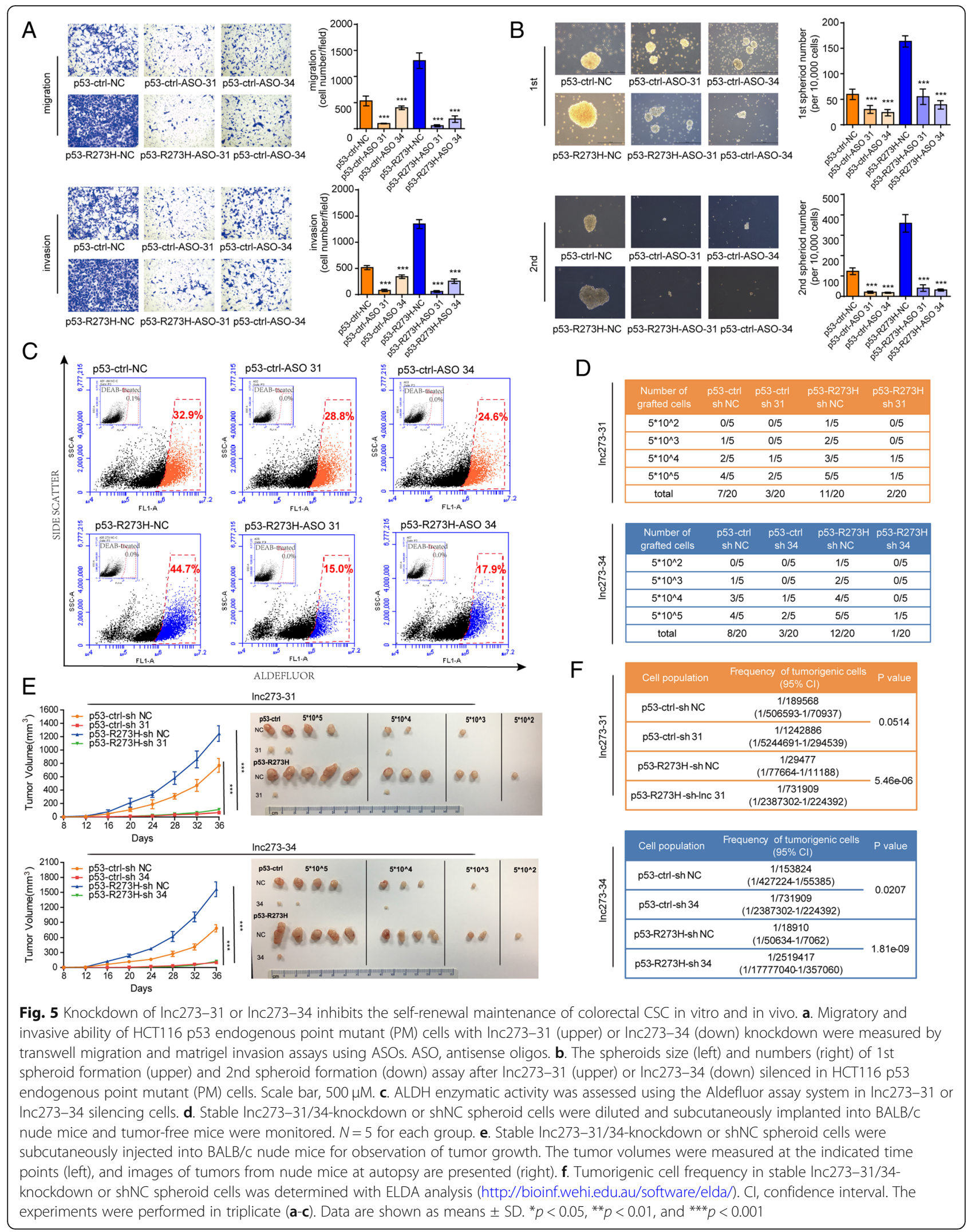




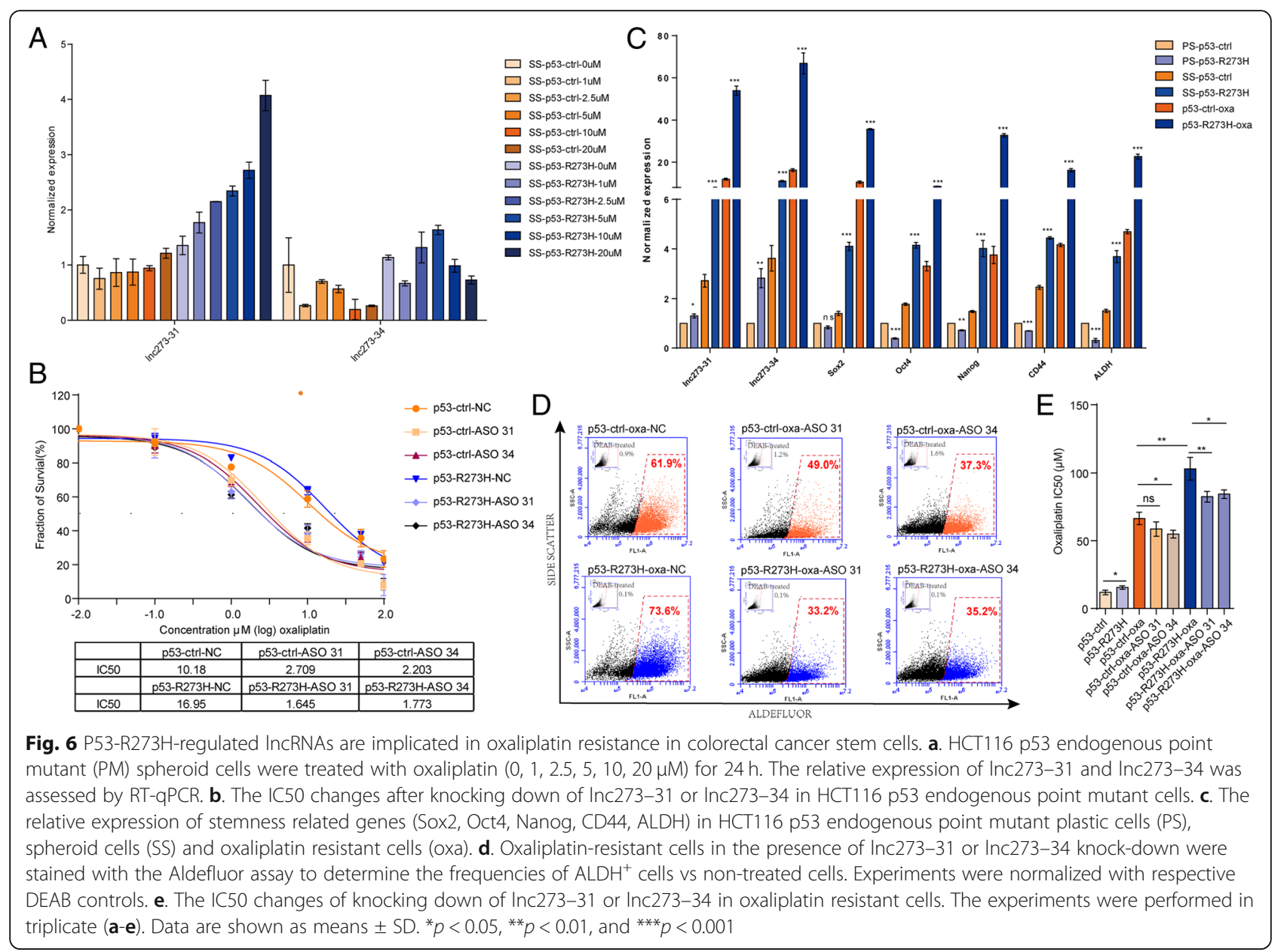

resistant cell lines than those in spheroid cells with 4and 11-fold increases, and the expression levels were higher in p53-R273H-oxa cells than in p53-ctrl-oxa cells (Fig. 6c).

We next found that the frequency of the $\mathrm{ALDH}^{+}$ population in oxaliplatin-resistant cell lines was higher than their parental cell lines (approximately 28.4\% of the cells were $\mathrm{ALDH}^{+}$in p53-ctrl cells and $42.1 \%$ in p53-R273H cells, while $61.9 \%$ in p53-ctrl-oxa cells and $73.6 \%$ in p53-R273H-oxa cells, Fig. 2d, 6d), indicating the oxaliplatin induction of CSCs. When knocking down of lnc273-31 or lnc273-34, the ALDH positive percentage in p53-ctrl-oxa cells dropped from $61.9 \%$ in NC cells to $49.0 \%$ or $37.3 \%$, respectively. While in p53$\mathrm{R} 273 \mathrm{H}$ cells, the frequency of the $\mathrm{ALDH}^{+}$population decreased from $73.6 \%$ in NC cells to $33.2 \%$ or $35.2 \%$ (Fig. 6d). Furthermore, knockdown of lnc273-31 or lnc273-34 in oxaliplatin-resistant cell lines decreased the IC50 of oxaliplatin more significantly in p53R273H-oxa than in p53-ctrl-oxa (Fig. 6e). In summary, lnc273-31 and lnc273-34 are implicated in oxaliplatin resistance in colorectal cancer.
The expression of Inc273-31 and Inc273-34 was significantly up regulated in CRC tissues with p53-R273H mutation as compared to $\mathrm{p} 53$ wildtype tissues

To explore the relationship between lnc273-31, lnc27334 and $\mathrm{p} 53-\mathrm{R} 273 \mathrm{H}$ mutation in colorectal cancer patients, we detected the expression level of $\operatorname{lnc} 273-31$ and lnc273-34 using RT-qPCR method in colorectal cancer tissue samples with or without p53-R273H mutation. The patients were divided into two groups according to their p53 status (Additional file 7). The expression level of lnc273-31 and lnc273-34 in colorectal cancer patients with p53-R273H mutation is higher than that in p53 wildtype group (Fig. 7a), and the difference was statistically significant $(p<0.001)$. Also we further analyze the association of age, gender, smoking, alcohol abuse, family history, lymphatic vessel, TNM stage and the levels of lncRNAs, and we found that IncRNA expression was nonrelevant with these clinicopathologic parameters (Fig. 7b, Additional file 1: Figure S8). All together, this finding further supported the previous results in our study, indicating that dysregulation of $\operatorname{lnc} 273-31$ or lnc273-34 expression have strong relevance with p53- 


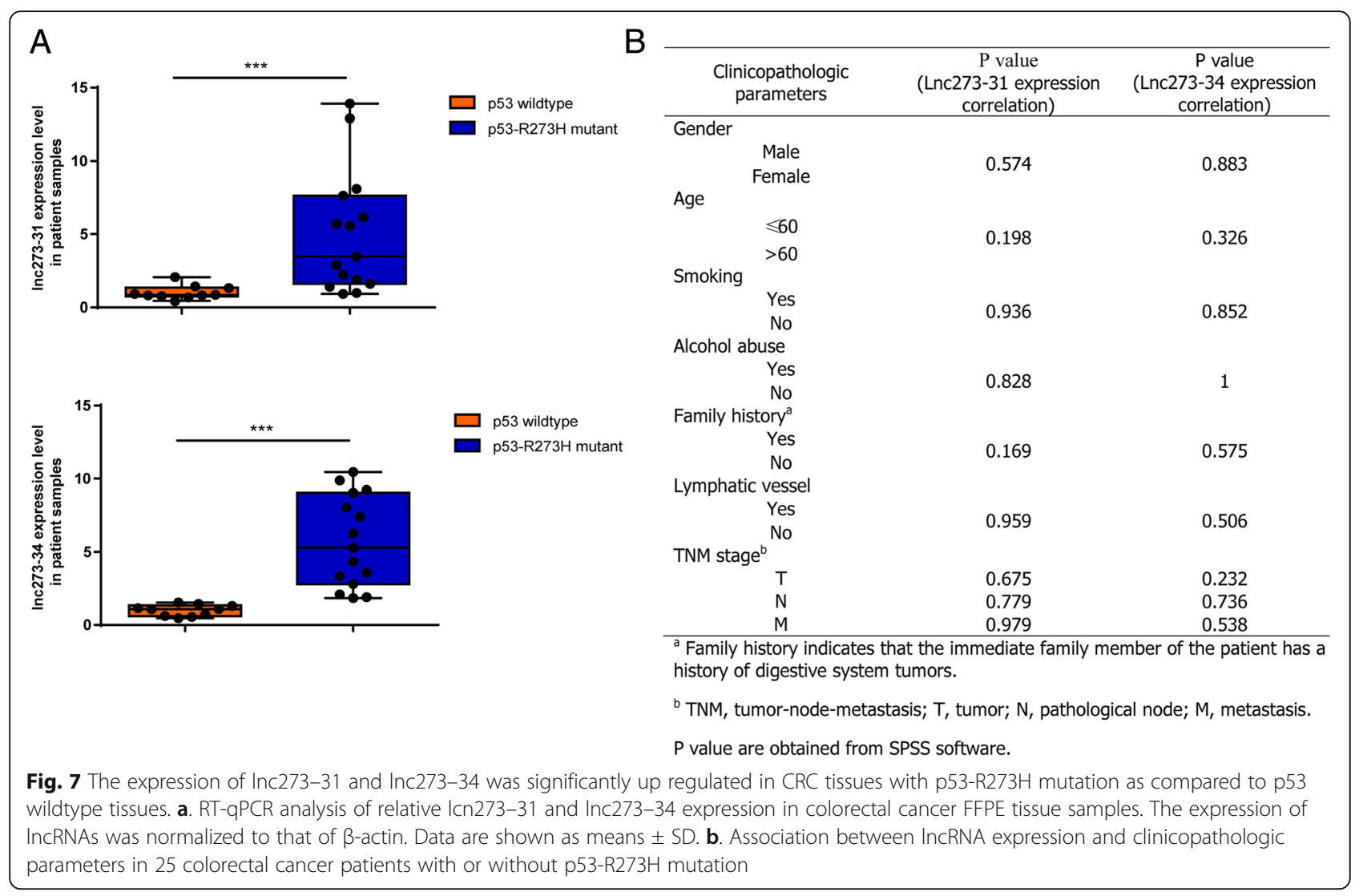

$\mathrm{R} 273 \mathrm{H}$, leading to priming of the self-renewal of colorectal CSCs and tumor initiation.

\section{Discussion}

Cancer stem cells have been considered as the core origin of the tumorigenesis and therapeutic resistance. For this reason, they have also been termed "tumor-initiating cells" [36]. As non-coding RNAs being found overwhelming majority of the transcripts, more and more studies have illustrated their roles in cancer development, as well as in cancer stem cells [37]. Given the robust transcript capability of mutant p53, we aimed to identify lncRNAs regulated by mutant $\mathrm{p} 53$, endowing cells with stem-like properties. The present study unveiled a subset of IncRNAs regulated by $\mathrm{p} 53-\mathrm{R} 273 \mathrm{H}$ to be essential in cancer stemness maintenance and chemoresistance, through RNA-seq combined with ChIP-seq.

Mutant p53 have been found to gain of function in tumor malignancy, and different types of mutation have diverse functions in cancer development, which further explains the gain-of-function of mutant p53. Previous studies on $\mathrm{p} 53-\mathrm{R} 175 \mathrm{H}$ or $\mathrm{p} 53-\mathrm{R} 248 \mathrm{~W}$ have mainly focused on their effects on tumor propagation [38, 39]. $\mathrm{P} 53-\mathrm{R} 273 \mathrm{H}$ has been shown to induce drug resistance through downregulating procaspase-3 levels [40] and promoting chronic inflammation and inflammation-associated cancer [41]. Most of these studies were based on mutant p53, as an oncogenic gene. Few studies have been reported on mutant p53 as an oncogenic transcription factor, to expore its function of regulating noncoding RNAs. Although there are several studies about mutant p53 affecting well-studied lncRNAs [42], in different cancer types, a systematic analysis of specific lncRNA networks regulated by p53-R273H in the CSC state was lacking until the present study was performed.

Mutant p53 gained of new function mainly dependent on its stabilization and accumulation, as well as altering the functions of proteins or transcript factors that partnering with in the nuclei $[43,44]$. In our study, Inc27331 and lnc273-34 were identified combined RNA-seq with ChIP-seq, indicating the directly or indirectly binding with p53-R273H mutant. Also we proved that both lnc273-31 and lnc273-34 were mostly localized in the nuclei (Additional file 1: Figure S6C), which further supported the clue. Mutant p53 exhibited an oncogenic function through EMT progress had been reported many times [45]. It was proposed that EMT was able to acquire the ability to self-renewal by inducing a CSC characteristic $[46,47]$. Many researchers have found that cancer cells showing EMT characteristics are resistant to chemotherapy, and cancer cells resistant to drugs exhibit EMT properties [48, 49]. Although EMT has been associated with 


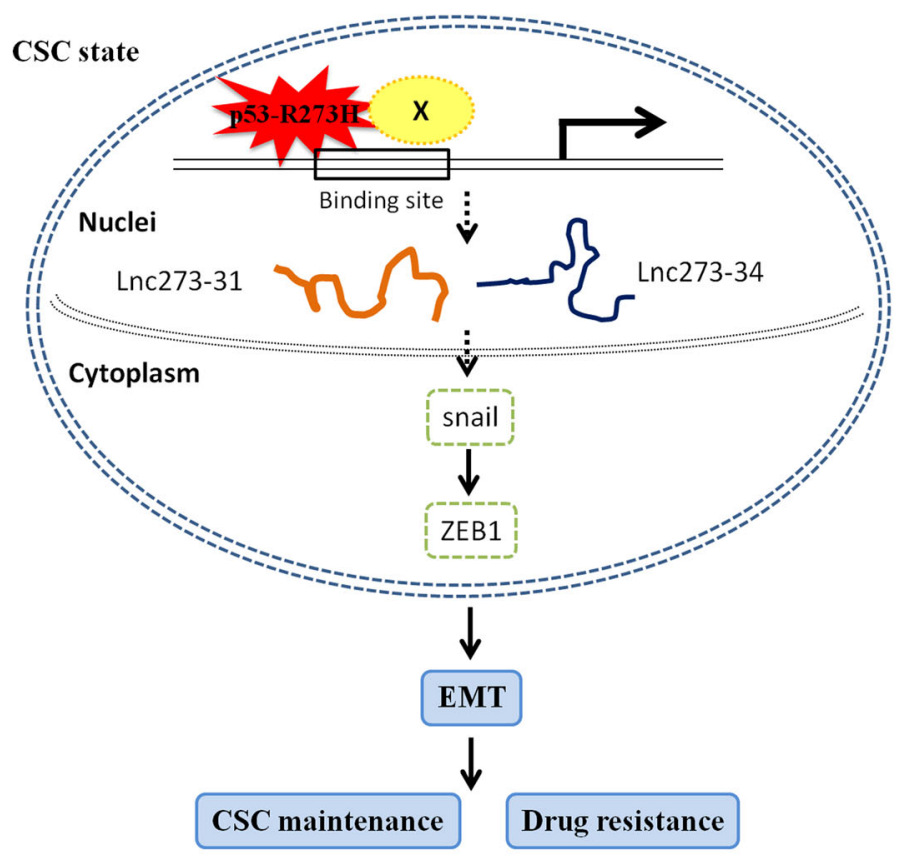

$X:$ unknown protein/TF

Fig. 8 Schematic illustration of the possible mechanism by which Inc273-31 and Inc273-34, regulated by p53-R273H, promotes CSC self-renewal expansion and chemoresistance in colorectal cancer

stemness properties, in our study, the expression of key factors of EMT was not significantly increased assessed by Western blot (data not shown), which is consistent with another assumption, indicating EMT and stemness are not necessarily linked [50]. However, the expression of ZEB1 and snail, key factors of EMT progress, was significantly decreased when lnc273-31 or lnc273-34 knocking down, especially in p53-R273H spheroid cells (Additional file 1: Figure S7B), indicating the core regulatory function of lnc273-31 and lnc273-34 in EMT. The ZEB1 and snail regulatory axis in CSCs has been explored in plenty of studies [51-55]. Thus, we proposed the possible mechanism by which lnc273-31 and lnc273-34 regulated by p53$\mathrm{R} 273 \mathrm{H}$ enhancing colorectal cancer stem cell stemness and chemoresistance (Fig. 8). Although these findings are insufficient, they all suggest an important role for lnc27331 and lnc273-34 in CSC maintenance and highlight the need for further investigation of the causal role of them in CSCs and chemoresistance and the underlying molecular mechanisms.

Recently, Ma et al. found that low expression of SH3PXD2A-AS1 (lnc273-34) is associated with colorectal cancer cell proliferation, migration and invasion in vitro as well as tumorigenesis inhibition in vivo, which validates the present sequencing results [56]. It is worth noting that the cell lines used in this article is SW480 and DLD1, which obtains the R273H and S241F mutation, respectively. S241F mutation is not as frequently mutated as $\mathrm{R} 273 \mathrm{H}$. However, both the $\mathrm{R} 273 \mathrm{H}$ and the
S241F mutation could affect DNA-binding activity, leading to dysregulation of p53 downstream target genes [57], suggesting another possible mechanism by which lnc273-31 and lnc273-34 accelerate colorectal cancer progression, which also needs further investigation.

LncRNAs play dynamic roles in chemoresistance [58] either with an intrinsic or an acquired chemoresistant phenotype through various mechanisms [59]. Although the chemoresistant mechanism was not specific clearly defined, the present results declared that a subset of lncRNAs involved in colorectal cancer stemness maintenance and to be essential for resistance to oxaliplatin. Thus, it is important to obtain a better understanding of the multiple components are involved in chemoresistance. Meanwhile, the present findings suggested that p53R273H-regulated lncRNAs may be novel indicators or predictors for the prognosis of patients with p53-R273H, especially patients with metastasis, and may be used to overcome drug resistance in colorectal cancer therapy.

\section{Conclusions}

In summary, the present study identified a set of lncRNAs regulated by p53-R273H, combined RNA-seq with ChIP-seq, required for colorectal cancer stem cell self-renewal, tumor propagation and chemoresistance. Further evidence suggested that lnc273-31 and lnc27334 may serve as promising indicators or predictors for patients with p53-R273H mutation and are vital for chemotherapy. 


\section{Additional files}

Additional file 1: Figure S1A. Western blot analysis of HCT116 p53-/over-expression p53 point mutants. Figure S2A. Schematic diagram of constructing HCT116 endogenous p53 point mutant (PM) cells. Figure S2B. Sanger sequencing of p53-R273H point mutant (R273H PM) representative cells. Figure S3. Global profiling and identification of p53-R273H-regulated IncRNAs. Figure S3A. Different types of transcripts. Figure S3B. Different types of noncoding transcripts. Figure S3C. A two-dimensional heatmap of 1957 IncRNAs. Figure S3D. Principal components analysis (PCA) for three independent replicates. The principal component accounted of p53-R273H and p53-ctrl were 85.7 and 69.6\% respectively. Figure S4A. Validation of differentially expressed 41 IncRNAs by RT-qPCR. Figure S5. Genome-wide analysis of p53-R273H-regulated protein coding genes in CSC state. Figure S5A. A two-dimensional heatmap of 307 mRNAs. Figure S5B. Principal components analysis (PCA) for three independent replicates. Figure S5C. Hierarchical clustering for three independent replicates. Figure S5D. Signaling pathway based on KEGG enrichment analysis of p53-R273Hregulated coding genes in CSC state. Figure S5E. GO biological processes enrichment analysis of p53-R273H-regulated coding genes in CSC state. Figure S5F. Regulatory network construction of TFs (dark blue), IncRNAs (red) and mRNAs (light green). The average degree of IncRNAs was 46.39, higher than 35.39, the average degree of protein coding genes. Figure S6A. ChIP-qPCR for validating of the binding of p53 and the promotor of Inc273-31 or Inc273-34. Figure S6B. The expression levels in ALDH positive and ALDH negative cells sorted by FACS. Figure S6C. Subcellular localization of Inc273-31 and Inc273-34 was analyzed by RT-qPCR upon biochemical fractionation of $\mathrm{p} 53-\mathrm{R} 273 \mathrm{H}$ speroid cells. Figure S7A. Quantitative real-time PCR analyzed the expression of stemnessrelated genes in HCT116 p53 PM cells. Figure S7B. Western blot analysis of ZEB1 and snail in Inc273-31 or Inc273-34 depletion cells. Figure S8. The association of age (S8A), gender (S8B), smoking (S8C), alcohol abuse (S8D), family history $(\mathrm{S} 8 \mathrm{E})$, lymphatic vessel $(\mathrm{S} 8 \mathrm{~F})$, TNM stage (S8G-I) and the expression levels of IncRNAs in 25 colorectal cancer patients with or without p53-R273H mutation. Table S1. Primers for qPT-PCR. Table S2. Purchased ASO pool sequences. Table S3. Primers for ChIP-qPCR. (DOCX 2058 kb)

Additional file 2: The list of differentially expressed IncRNAs. (XLSX $11 \mathrm{~kb}$ ) Additional file 3: The results of KEGG and GO analysis. (XLSX $18 \mathrm{~kb}$ ) Additional file 4: The list of differentially expressed protein coding genes (PCGs). (XLSX $128 \mathrm{~kb}$ )

Additional file 5: LncRNA annotation. (XLSX $107 \mathrm{~kb}$ )

Additional file 6: The list of IncRNAs analyzed by RNA-seq combined with ChIP-seq. (XLSX 29 kb)

Additional file 7: Clinical patient information. (XLSX $11 \mathrm{~kb}$ )

\section{Abbreviations}

ChIP-seq: ChIP-sequencing; CRC: Colorectal cancer; CSC: Cancer stem cell; ELDA: Extreme limiting dilution analysis; GO: Gene Ontology; GOF: Gain of oncogenic functions; KEGG: Kyoto Encyclopedia of Genes and Genomes; IncRNA: long noncoding RNA; LOF: Loss of tumor-suppressive functions; NC: Negative control; RNA-seq: RNA-sequencing

\section{Acknowledgements}

We thank Prof. Dong Wang for assistance with bioinformatics analysis.

\section{Authors' contributions}

WS, YZ and HZ conceived and designed this study. YZ performed most of the biological experiments. YL performed all the bioinformatics analysis. JS participated in all the biological validation experiments. $F W, K L, R H, X W, T J$, $X G, Y L, X C, Z L, Y Z, H H$ and $W L$ provided some experimental support; XB, JY, $L W, S M, J C$ and BD provided critical suggestions on manuscript preparation; $Y Z$, WS and $Y L$ prepared the manuscript with the help from all coauthors. All authors read and approved the final manuscript.

\section{Funding}

This work was supported by grants from CAMS Innovation Fund for Medical Sciences (2016-I2M-1-001, 2017-I2M-3-009, 2017-12 M-4-002), the National
Key Research and Development Program of China (No. 2018YFC1003500), the National Key Basic Research Program of China (2015CB943001), the National Natural Science Foundation of China (81672472, 81672461), the State Key Laboratory Special fund from the Ministry of Science (2060204), the State Key Project on Infection Diseases of China (2017ZX10201021-007-003).

\section{Availability of data and materials}

The datasets used and/or analyzed during the current study are available from the corresponding author on reasonable request.

\section{Ethics approval and consent to participate}

Animal experiments were performed with the approval of the Peking Union Medical College Animal Care and Use Committees.

\section{Consent for publication}

Not applicable.

\section{Competing interests}

The authors declare that they have no competing interests.

\section{Author details}

'Department of Biochemistry and Molecular Biology, State Key Laboratory of Medical Molecular Biology, Institute of Basic Medical Sciences Chinese Academy of Medical Sciences, School of Basic Medicine Peking Union Medical College, Beijing 100005, China. ${ }^{2}$ Department of Hepatobiliary Surgery, State Key Laboratory of Molecular Oncology, National Cancer Center/National Clinical Research Center for Cancer/Cancer Hospital, Chinese Academy of Medical Sciences and Peking Union Medical College, Beijing 100021, China. ${ }^{3}$ Department of Pathology, State Key Laboratory of Molecular Oncology, National Cancer Center/National Clinical Research Center for Cancer/Cancer Hospital, Chinese Academy of Medical Sciences and Peking Union Medical College, Beijing 100021, China. ${ }^{4}$ Department of Medical Biology, School of Basic Medical Sciences, Hubei University of Medicine, Shiyan 442000, China.

Received: 14 April 2019 Accepted: 9 August 2019

Published online: 28 August 2019

\section{References}

1. Valastyan S, Weinberg RA. Tumor metastasis: molecular insights and evolving paradigms. Cell. 2011;147(2):275-92.

2. Karsa LV, Lignini TA, Patnick J, Lambert $R$, Sauvaget $C$. The dimensions of the CRC problem. Best Pract Res Clin Gastroenterol. 2010;24(4):381-96.

3. Batlle E, Clevers H. Cancer stem cells revisited. Nat Med. 2017:23(10):1124-34.

4. Clarke MF, Dick JE, Dirks PB, Eaves CJ, Jamieson CH, Jones DL, Visvader J, Weissman IL, Wahl GM. Cancer stem cells-perspectives on current status and future directions: AACR work shop on cancer stem cells. Cancer Res Cancer Res. 2006;66(19):9339-44.

5. Kastenhuber ER, Lowe SW. Putting p53 in context. Cell. 2017;170(6):1062-78.

6. Petitjean A, Mathe E, Kato S, Ishioka C, Tavtigian SV, Hainaut P, Olivier M. Impact of mutant p53 functional properties on TP53 mutation patterns and tumor phenotype: lessons from recent developments in the IARC TP53 database. Hum Mutat. 2007;28(6):622-9.

7. Hosain SB, Khiste SK, Uddin MB, Vorubindi V, Ingram C, Zhang S, Hill RA, Gu $X$, Liu YY. Inhibition of glucosylceramide synthase eliminates the oncogenic function of p53 R273H mutant in the epithelial-mesenchymal transition and induced pluripotency of colon cancer cells. Oncotarget. 2016;7(37):60575-92.

8. Yan H, Bu P. Non-coding RNAs in cancer stem cells. Cancer Lett. 2018;421: 121-6.

9. Kogo R, Shimamura T, Mimori K, Kawahara K, Imoto S, Sudo T, Tanaka F, Shibata K, Suzuki A, Komune S, Miyano S, Mori M. Long noncoding RNA HOTAIR regulates polycomb-dependent chromatin modification and is associated with poor prognosis in colorectal cancers. Cancer Res. 2011; 71(20):6320-6.

10. Ge X, Chen Y, Liao X, Liu D, Li F, Ruan H, Jia W. Overexpression of long noncoding RNA PCAT-1 is anovel biomarker of poor prognosis in patients with colorectal cancer. Med Oncol. 2013;30(2):588.

11. Kopp F, Mendell JT. Functional classification and experimental dissection of long noncoding RNAs. Cell. 2018;172(3):393-407. 
12. Hu WL, Jin $L, X u A$, Wang $Y F$, Thorne RF, Zhang XD, Wu M. GUARDIN is a p53-responsive long non-coding RNA that is essential for genomic stability. Nat Cell Biol. 2018;20(4):492-502.

13. S'anchez Y, Segura V, Marı'n-Be'jar O, Athie A, Marchese FP, Gonza'lez J, Bujanda L, Guo S, Matheu A, Huarte M. Genome-wide analysis of the human p53 transcriptional network unveils a IncRNA tumour suppressor signature. Nat Commun. 2014;5:5812.

14. Weisz $L$, Oren $M$, Rotter $V$. Transcription regulation by mutant p53. Oncogene. 2007;26(15):2202-11.

15. Quante T, Otto B, Brázdová M, Kejnovská I, Deppert W, Tolstonog GV. Mutant p53 is a transcriptional co-factor that binds to G-rich regulatory regions of active genes and generates transcriptional plasticity. Cell Cycle. 2012;11(17):3290-303.

16. Zhang M, Miao F, Huang R, et al. RHBDD1 promotes colorectal cancer metastasis through the Wnt signaling pathway and its downstream target ZEB1. J Exp Clin Cancer Res. 2018;37(1):22.

17. Han XY, Wei B, Fang JF, et al. Epithelial-mesenchymal transition associates with maintenance of stemness in spheroid-derived stem-like colon cancer cells. PLoS One. 2013;8(9):e73341.

18. McDermott M, Eustace AJ, Busschots S, et al. In vitro development of chemotherapy and targeted therapy drug-resistant Cancer cell lines: a practical guide with case studies. Front Oncol. 2014;4:40.

19. Jensen NF, Stenvang J, Beck MK, et al. Establishment and characterization of models of chemotherapy resistance in colorectal cancer: towards a predictive signature of chemoresistance. Mol Oncol. 2015;9(6):1169-85.

20. Xie M, Zhang L, He CS. Activation of Notch-1 enhances epithelialmesenchymal transition in gefitinib-acquired resistant lung cancer cells. J Cell Biochem. 2012;113(5):1501-13.

21. Lister $R$, et al. Highly integrated single-base resolution maps of the epigenome in Arabidopsis. Cell. 2008;133:523-36.

22. Mortazavi A, Williams BA, McCue K, Schaeffer L, Wold B. Mapping and quantifying mammalian transcriptomes by RNA-seq. Nat Methods. 2008;5: 621-8.

23. Cloonan N, et al. Stem cell transcriptome profiling via massive-scale mRNA sequencing. Nat Methods. 2008;5:613-9.

24. Langmead B, Trapnell C, Pop M, Salzberg SL. Ultrafast and memory-efficient alignment of short DNA sequences to the human genome. Genome Biol. 2009; 10:R25.

25. Zhang Y, et al. Model-based analysis of ChIP-Seq (MACS). Genome Biol. 2008;9:R137.

26. Heinz S, et al. Simple combinations of lineage-determining transcription factors prime cis-regulatory elements required for macrophage and B cell identities. Mol Cell. 2010;38:576-89.

27. Zhang X, Guo C, Chen Y, Shulha HP, Schnetz MP, LaFramboise T, Bartels CF, Markowitz S, Weng Z, Scacheri PC, Wang Z. Epitope tagging of endogenous proteins for genome-wide ChIP-chip studies. Nat Methods. 2008;5(2):163-5

28. Huang EH, Hynes MJ, Zhang T, Ginestier C, Dontu G, Appelman H, et al. Aldehyde dehydrogenase 1 is a marker for normal and malignant human colonic stem cells (SC) and tracks SC overpopulation during colon tumorigenesis. Cancer Res. 2009:69:3382e3389.

29. Chen J, Xia Q, Jiang B, Chang W, Yuan W, Ma Z, et al. Prognostic value of cancer stem cell marker ALDH1 expression in colorectal cancer: a systematic review and meta-analysis. PLoS One. 2015;10:1e15.

30. Prieto-Vila M, Takahashi RU, Usuba W, Kohama I, Ochiya T. Drug resistance driven by Cancer stem cells and their niche. Int J Mol Sci. 2017;1:18(12).

31. Spano JP, Milano G, Rixe C, Fagard R. JAK/STAT signalling pathway in colorectal cancer: a new biological target with therapeutic implications. Eur J Cancer. 2006;42(16):2668-70.

32. Lee SY, Jeong EK, Ju MK, Jeon HM, Kim MY, Kim CH, Park HG, Han SI, Kang HS. Induction of metastasis, cancer stem cell phenotype, and oncogenic metabolism in cancer cells by ionizing radiation. Mol Cancer. 2017:16(1):10.

33. Redelman-Sidi G, Binyamin A, Gaeta I, Palm W, Thompson CB, Romesser PB, Lowe SW, Bagul M, Doench JG, Root DE, Glickman MS. The canonical Wnt pathway drives macropinocytosis in Cancer. Cancer Res. 2018;78(16):4658-70

34. Patel AP, Tirosh I, Trombetta JJ, Shalek AK, Gillespie SM, Wakimoto H, Cahill DP, Nahed BV, Curry WT, Martuza RL, Louis DN, Rozenblatt-Rosen O, Suvà ML, Regev A, Bernstein BE. Single-cell RNA-seq highlights intratumoral heterogeneity in primary glioblastoma. Science. 2014 344(6190):1396-401.

35. Wu SM, Liu H, Huang PJ, Chang IY, Lee CC, Yang CY, Tsai WS, Tan BC. circlncRNAnet: an integrated web-based resource for mapping functional networks of long or circular forms of noncoding RNAs. Gigascience. 2018; 7(1):1-10.

36. Reya T, Morrison SJ, Clarke MF, Weissman IL. Stem cells, cancer, and cancer stem cells. Nature. 2001:414:105-11.

37. Huarte M. The emerging role of IncRNAs in cancer. Nat Med. 2015;21(11): 1253-61.

38. Senapati P, Dey S, Sudarshan D, Das S, Kumar M, Kaypee S, Mohiyuddin A, Kodaganur GS, Kundu TK. Oncogene c-fos and mutant R175H p53 regulate expression of Nucleophosmin implicating cancer manifestation. FEBS J. 2018;285(18):3503-24.

39. Hanel W, Marchenko N, Xu S, Yu SX, Weng W, Moll U. Two hot spot mutant p53 mouse models display differential gain of function in tumorigenesis. Cell Death Differ. 2013;20(7):898-909.

40. Wong RP, Tsang WP, Chau PY, Co NN, Tsang TY, Kwok TT. p53-R273H gains new function in induction of drug resistance through down-regulation of procaspase-3. Mol Cancer Ther. 2007;6(3):1054-61.

41. Cooks T, Pateras IS, Tarcic O, Solomon H, Schetter AJ, Wilder S, Lozano G, Pikarsky E, Forshew T, Rozenfeld N, Harpaz N, Itzkowitz S, Harris CC, Rotter V, Gorgoulis VG, Oren M. Mutant p53 prolongs NF-KB activation and promotes chronic inflammation and inflammation-associated colorectal cancer. Cancer Cell. 2013;23(5):634-46.

42. Pruszko M, Milano E, Forcato M, Donzelli S, Ganci F, Di Agostino S, De Panfilis S, Fazi F, Bates DO, Bicciato S, Zylicz M, Zylicz A, Blandino G, Fontemaggi $\mathrm{G}$. The mutant p53-ID4 complex controls VEGFA isoforms by recruiting IncRNA MALAT1. EMBO Rep. 2017;18(8):1331-51.

43. Oren M, Rotter V. Mutant p53 gain-of-function in cancer. Cold Spring Harb Perspect Biol. 2010;2(2):a001107.

44. Kim MP, Lozano G. Mutant p53 partners in crime. Cell Death Differ. 2018; 25(1):161-8

45. Shetzer $Y$, Molchadsky A, Rotter $V$. Oncogenic mutant p53 gain of FunctionNourishes the vicious cycle of TumorDevelopment and Cancer stem-cell formation. Cold Spring Harb Perspect Med. 2016:3:6(10).

46. Mani SA, Guo W, Liao MJ, Eaton EN, Ayyanan A, Zhou AY, et al. The epithelial-mesenchymaltransition generates cells with properties of stem cells. Cell1. 2008;33:704-15.

47. Chang L, Graham PH, Hao J, et al. Acquisition of epithelialmesenchymal transition and cancer stem cell phenotypes is associated with activation of the PI3K/Akt/mTOR pathway in prostate cancer radioresistance. Cell Death Dis. 2013:4:e875.

48. Thiery JP, Acloque H, Huang RY, Nieto MA. Epithelial-mesenchymal transitions in developmentand disease. Cell. 2009;139:871-90.

49. Yang AD, Fan F, Camp ER, van Buren G, Liu W, Somcio R, et al. Chronic oxaliplatin resistance inducesepithelial-to-mesenchymal transition in colorectal cancercell lines. Clin Cancer Res. 2006;12:4147-53.

50. Brabletz T. EMT and MET in metastasis: where are the cancer stem cells? Cancer Cell. 2012;22(6):699-701

51. Cieply B, Farris J, Denvir J, et al. Epithelial-mesenchymal transition and tumor suppression are controlled by a reciprocal feedback loop between ZEB1 and Grainyhead-like-2. Cancer Res. 2013:73(20):6299-309.

52. Choi HJ, Park JH, Park M, et al. UTX inhibits EMT-induced breast CSC properties by epigenetic repression of EMT genes in cooperation with LSD1 and HDAC1. EMBO Rep. 2015;16(10):1288-98.

53. Lehmann W, Mossmann D, Kleemann J, et al. ZEB1 turns into a transcriptional activator by interacting with YAP1 in aggressive cancer types. Nat Commun. 2016;7:10498.

54. Zhang $Y, X u L, L i ~ A$, et al. The roles of ZEB1 in tumorigenic progression and epigenetic modifications. Biomed Pharmacother. 2019;110:400-8.

55. Moyret-Lalle C, Ruiz E, Puisieux A. Epithelial-mesenchymal transition transcription factors and miRNAs: "plastic surgeons" of breast cancer. World I Clin Oncol. 2014:5(3):311-22.

56. Ma Z, Peng P, Zhou J, Hui B, Ji H, Wang J, Wang K. Long non-coding RNA SH3PXD2A-AS1 promotes cell progression partly through epigenetic silencing P57 and KLF2 in colorectal Cancer. Cell Physiol Biochem. 2018;46(6):2197-214.

57. Parrales A, Iwakuma T. Targeting Oncogenic Mutant p53 for Cancer Therapy. Front Oncol. 2015;5:288.

58. Ren J, Ding L, Zhang D, Shi G, Xu Q, Shen S, Wang Y, Wang T, Hou Y. Carcinoma-associated fibroblasts promote the stemness and 
chemoresistance of colorectal cancer by transferring exosomal IncRNA H19. Theranostics. 2018;8(14):3932-48.

59. Malhotra A, Jain M, Prakash H, Vasquez KM, Jain A. The regulatory roles of long non-coding RNAs in the development of chemoresistance in breast cancer. Oncotarget. 2017;8(66):110671-84.

\section{Publisher's Note}

Springer Nature remains neutral with regard to jurisdictional claims in published maps and institutional affiliations.

Ready to submit your research? Choose BMC and benefit from:

- fast, convenient online submission

- thorough peer review by experienced researchers in your field

- rapid publication on acceptance

- support for research data, including large and complex data types

- gold Open Access which fosters wider collaboration and increased citations

- maximum visibility for your research: over $100 \mathrm{M}$ website views per year

At $\mathrm{BMC}$, research is always in progress.

Learn more biomedcentral.com/submissions 